\title{
Animal Personas: Representing Dog Stakeholders in Interaction Design
}

\author{
Ilyena Hirskyj-Douglas \\ University of Central Lancashire \\ Preston, PR1 2HE \\ ihirskyj-douglas@uclan.ac.uk
}

\author{
Janet C Read \\ University of Central Lancashire \\ Preston, PR1 2HE \\ jcread@uclan.ac.uk
}

\author{
Matthew Horton \\ University of Central Lancashire \\ Preston, PR1 2HE \\ mplhorton@uclan.ac.uk
}

\begin{abstract}
This paper describes the development and evaluation of animal personas for use in the design and development of interactive product. Building from 196 dog owner reports describing dog behaviours and explaining how they interact with digital media devices, six dog personas are created as examples of both how these can be presented but also of how they can be derived. The created personas are then evaluated by experts in terms of their value to the Animal Computer Interaction Community. These experts reported that the personas were useful commenting on their use across $\mathrm{ACl}$. The contributions of this paper are the datastore used to generate the personas, the method used and the persona set.
\end{abstract}

Animal Computer Interaction. Dog Computer Interaction. Personas. User-centered design.

\section{INTRODUCTION}

This paper describes the development of a set of personas for Dog Computer Interaction (DCl) which is a subfield of the recently developing Animal Computer Interaction $(\mathrm{ACl})$ field. These two communities are keen to develop animal friendly products and thus, the aim here is to bring a wellused Human Computer Interaction $(\mathrm{HCl})$ method to $\mathrm{ACl}$. The paper contributes a product as well as an explanation of the method used so that its findings can be useful to other areas of $\mathrm{ACl}$. The personas created in this study are specifically for $\mathrm{DCl}$ with media systems and therefore add to the current toolset of methods for ACl.

The goal in designing systems for users is to both create a positive user experience and to have high acceptance (Moser et al., 2012). This is underpinned by two success factors of involving the end user and understanding their needs. This is particularly important in any research space where there are special users (Moser et al., 2012), and thus potentially where the users are animals. Although $\mathrm{ACl}$ researchers aim to involve the end user in design and fully understand the end users' needs, there can be considerable guesswork. This issue was noted in the ACI@BHCl workshop (2015), where $\mathrm{ACl}$ researchers concluded that design can be a game of approximation in which researchers often implement what they believe is best practice relying on data from animal behaviorists and from their own knowledge.
Enhancing system designers' understanding of animals' needs is expected to assist researchers to build more successful systems. It is towards this goal of supporting $\mathrm{DCl}$ media systems' implementation that this paper aims to support. This aim also works towards the overall encompassed goal of creating transferable methods between $\mathrm{ACl}$ and $\mathrm{HCl}$ to enrich both fields (Hirskyj-Douglas et al., 2016). The sharable goal between these two fields, $\mathrm{ACl}$ and $\mathrm{HCl}$, of designing products for users who are beyond the normal borders of design, can strengthen both fields through connected thinking and interchangeable methods (Mancini., 2011).

To accomplish these goals, a growing trend in $\mathrm{ACl}$ is to design using an animal centric approach (Hirskyj-Douglas et al., 2016; Mancini, 2016). This animal centered approach aims at including the animal within the design process by making the animal an intrinsic part of the system (HirskyjDouglas \& Read., 2014; Mancini., 2016). In ACl, as in $\mathrm{HCl}$, this user involvement can be difficult to achieve as there may be restrictions on access to certain animals, there can be a shortage of participants and there could be some danger to the researcher. When working with animals there are also ethical considerations to be taken into account as the animal has limited abilities in expressing itself (Mancini, 2016). Traditional methods such as interviews and questionnaires cannot be used with animals to determine requirements. Owners can be quizzed but, with so much intra-animal variation, either large data sets are needed which require extensive analytical interpretation, or, in singular instances, the results can be so individualistic that design is difficult. Overall, the task of acquiring and 
interpreting end-user responses in $\mathrm{ACl}$ can pose a very real difficulty - this is not entirely different from some areas of $\mathrm{HCl}$, such as in the design of technology for babies.

Building and developing personas is known to assist in these situations. Initially developed by Cooper (1999) for $\mathrm{HCl}$, personas are models of users focusing on their goals during an interaction with an artefact (Blomkvist, 2002). Literature offers four different perspectives on personas: Alan Coopers goal-directed perspective, Grudin, Pruitt \& Adlins role-based perspective, and Nielsens engaging and fiction-based perspectives (Nielsen, 2016). Within these persona methods, as Moser et al. (2012) point out, there are two main research topics: 1) making them more memorable for those who need them and 2 ) the study of how to develop and create personas.

As a concept, personas in $\mathrm{ACl}$ are not novel, having been explored in two previous instances for particular design applications, one in dog assistant alarms (Robinson et al., 2014) and one for individual chicken users in food systems (Frawley \& Dyson, 2014). With dogs being the most researched animal in $\mathrm{ACl}$, building personas for $\mathrm{DCl}$ builds from Robinson et al. (2014)'s foundation of created UCD dog computer systems. The personas generated here will additionally be concerned with the dog as a user of DCl media technologies.

This work adds to Moser et al.'s (2012) second focus on personas of development and creation through an analysis of methods situated in the current $\mathrm{DCl}$ focus. This is done by creating questionnaires for dog owners to form a data storehouse, and from this crafting six role-based personas for $\mathrm{DCl}$ media systems split by breed, age and living status. These personas are validated for their usability by contacting $\mathrm{DCl}$ researchers and by putting them against current technology. The overarching goal of this paper is to develop and validate personas for media $\mathrm{DCl}$ systems from collected data for both rescue and pet dogs adding to both the $\mathrm{ACl}$ and $\mathrm{HCl}$ field from real data strengthening the pathway between the two fields and for future $\mathrm{ACl}$ researchers. By testing this transference, it builds better methods for voiceless users to represent enduser requirements, both non-human and human, allowing designers to base their decisions from real data personas by avoiding assumptions making the designed technology User Center Design (UCD).

\section{RELATED WORK}

In recent years, the way in which researchers work with animals in science has changed. It is no longer about what is lawfully ethical with animals as research instruments, in a cost vs. harm scenario (Vaataja et al., 2012), instead, it is now a progressive stance of valuing the animal, as illustrated in the welfare-centred ethics framework of
Mancini (2016), as a research participant. Against this background, of increasing ethical and societal stance, the approach of designing in an animal centred way has emerged as a key theme for $\mathrm{ACl}$. This is not just about making the animal involved in the design, but is also a philosophical stance of acknowledging the direct, and indirect, entanglements that we, as humans, have with other species and organisms (Haraway, 2008). This is both important when the animal is the direct user and an indirect user (Weilenmann \& Juhlin, 2011).

Designs of these new animal-centric technologies have typically emerged from the perspective of the human technology designer who has a vested interest in the technology solution - often guessing at the animals end-users' needs. As a result, often the animal end-user is only involved in the technology towards the latter stages, such as usertesting when the majority of the systems options have already been designed. Less studied, is codesigning with the animal from the onset; primarily due to there being a lack of methods to involve this specialist end-user and a debate within $\mathrm{ACl}$ around the ability to co-design. As such, effective methods to help $\mathrm{ACl}$ system designers during the conception phase of technology are still in their infancy.

Challenges for $\mathrm{ACl}$ are both in understanding the specific animals' technology relationships but also in designing methods and tools that allow the study of these different animals (Aspling et al. 2015). Frameworks to aid this understanding have been constructed for $\mathrm{ACl}$ technology in interaction design (Tan et al., 2006), ubiquitous computing (Mancini et al., 2014) and games design (Mancini et al., 2014, Racca et al., 2010). Some of these aim to reveal the role that technology plays within a human-animal interaction (Mancini et al., 2014, Westerlaken \& Gualen, 2014), whilst others aim to minimize the human role to more fully design for the animals' unique needs (Hirskyj-Douglas et al., 2016).

Current personas created within $\mathrm{ACl}$, by Robinson et al. (2014) and Frawley \& Dyson (2012) are scenario based. When $\mathrm{ACl}$ researchers design systems, an ethnographical approach of limited studies, broken down into species as appropriate, is often merged with knowledge of animal behaviour and design experience. Whilst this is helpful, it typically does not focus the designer on the particular needs of the animal end-user within the specific context.

\subsection{Personas}

Personas are archetypical resemblances of a user profile of a real or potential user (Blomkvist, 2002). These personas show patterns of the system users' behaviours, goals, motives and information needs, all merged into a single fictional description of a user (Blomkvist, 2002). With a history in marketing (Moore, 1991), personas were introduced by Cooper 
(1999) into product design with the aim to fight the then common problem of communicating the distinct current user to the development team. Cooper (1999) suggested that the creation of a persona should be loosely based upon interviews and observations, introducing what is latterly referred to as a goal-directed perspective. With this approach there was no real thrust to find representative users (Sinha, 2003). Later, contrasting this, to make personas, Grudin \& Pruitt (2002) used quantitative and qualitative information to find the representative user, - this approach being referred to as taking a role perspective. Grudin and Prout (2002) used methods such as market and field studies, focus groups etc. to inform their persona creation process. Leading on from this, there is also the engaging perspective which is rooted in the ability of the stories told by the persona set to generate and secure involvement and insight (Nielsen, 2012). This perspective aims to avoid stereotypical users by involving the designer in the lives of the persona (Nielsen 2012; Nielsen, 2011). Lastly, there are fictional-based personas which unlike the previous persona methods do not include data as the basis for persona description (Nielsen, 2016). Instead this method uses the designers' intuition and assumptions.

\subsubsection{Previous Personas in $\mathrm{ACl}$}

Within $\mathrm{ACl}$ there have previously been two instances of personas (Robinson et al., 2014; Frawley \& Dyson, 2012). Robinson et al. (2014) explored making scenario based personas for assistant diabetic dogs for a particular application. They also explored making a partnership persona to interlink the dog and the dog owner. The personas were based upon patterns the research team had observed in a fictional perspective manner (Robinson et al., 2014). The personas included a description containing quantitative and qualitative data such as age, breed, good with children, travel habits etc. in a paragraph descriptive format (Figure $1)$.

\footnotetext{
Dottie (Fig. 2) is a medium-small, five year old terriertype mixed-breed assistance dog. Her job is to warn her owner, who has Type 1 Diabetes, if the owner's blood sugar levels are going too low. Dottie goes everywhere, including planes, with her owner. She avoids all other animals, unless they are dogs she already knows well. Dottie isn't too keen when her owner's children have made high-pitch noises and gets very worked up when she hears a neighbor's cat screeching. Dottie isn't especially playful with toys, but loves running around in circles at high speeds outside. She is shy in new situations and her owner has noticed that Dottie is less likely to warn him about his dropping blood sugar if they are in an environment with a lot of distractions or unfamiliar faces.
}

Figure 1: Robinson et al., (2014) Personas paragraph

In presenting these personas, Robinson et al. (2014) emphasized the need to include size, attitude and play behaviour. Mirroring the positions of Grudin \&
Pruitt (2002) and Pruitt \& Adlin (2006), ACl personas' work emphasizes the need for the persona method as a complementary method where the personas are a reference point (Robinson et al., 2014). In terms of usefulness, Robinson et al (2014) found personas useful to demonstrate to designers of $\mathrm{ACl}$ systems and other disciplines the needs of the end-user but concluded that, going forward, ethnographic data (quantitative and qualitative real data) be used to create richer personas based on real animals, to assist $\mathrm{ACl}$ designers Frawley \& Dyson (2012) created goal-directed chicken personas for an agriculture egg laying farm (Figure 2 ). The information that fed these personas was obtained from interviews with the farmers and with observation of hens in both commercial and suburban (backyard) settings. In this way they perceived the personhood of the animals (Milton, 2005), whilst admitting that the persona created is a human and semiotic artefact with the understanding being a more human perspective of the chickens.

\begin{tabular}{|c|c|}
\hline Name: & Betsy \\
\hline Age: & 12 months \\
\hline Breed: & ISA Brown \\
\hline Lives: & $\begin{array}{l}\text { In a mobile hen house in the New South } \\
\text { Wales'Southern Highlands, Australia. }\end{array}$ \\
\hline \multicolumn{2}{|c|}{$\begin{array}{l}\text { Betsy started laying eggs at about } 6 \text { months of age and is } \\
\text { working at laying } 1 \text { egg a day, although on a good day } \\
\text { she'll sometimes lay two. She wakes up at dawn and } \\
\text { takes herself to bed at dusk. In the mobile hen house } \\
\text { there are } 300 \text { other ISA Browns all of whom lay eggs, } \\
\text { and scratch around the field during the day. She has a } \\
\text { curious disposition and if doors are left open she'll go in } \\
\text { and explore. She once got into the farmhouse. To allow } \\
\text { her to move around safely the farm has several large } \\
\text { Maremma dogs- that are trained to guard her and the } \\
\text { other girls. Though as a pullet she found the dogs scary } \\
\text { she is now used to their presence on the farm. She likes } \\
\text { green vegetables and has several times broken into the } \\
\text { vegetable patch when the electric fence was turned off. } \\
\text { She enjoys being around the human farmers and doesn't } \\
\text { mind being picked up- in fact there is a spot under her } \\
\text { chin that she quite likes having stroked. However she is } \\
\text { soon eager to be back on the ground with the other } \\
\text { chickens, eating, pecking and taking dust baths in the } \\
\text { dirt under the trees. }\end{array}$} \\
\hline
\end{tabular}

Figure 2: Frawley and Dyson (2012; Table 1) Personas for Chickens.

To reinforce this perspective, Frawley \& Dyson (2012) employed the use of third person linguistically to remind the reader that this is an outside perspective on the chicken. The personas were used as an evaluation tool and they were useful to highlight the tensions between animal welfare and a system that creates animals' death (Frawley \& Dyson, 2012). In this way the persona tool was used for both an exploration of assumptions and stakeholders' interests but also as a reflective tool (Frawley \& Dyson, 2012).

This work seeks to build incrementally from the two previous instances of $\mathrm{ACl}$ personas for both improvement and to create a specific set of 
personas for dogs use of screen systems. The difference within this work from Frawley \& Dyson (2012) and Robinson et al. (2014) is both a varying set of personas and the specification of the dog screen focus.

\subsection{Dogs and the Design of Media for them}

Dogs can take on different roles within $\mathrm{ACl}$ as working animals (Mancini et al., 2015), playful interactors (Pons et al., 2015) and supporters of human roles (Robinson et al., 2014). These different $\mathrm{ACl}$ animal functions have different objectives and roles within systems with the animal presenting different behaviours towards different instances. As these systems each have different objectives and roles, personas are better to be developed that are associated with a single role. In the present work this role is of the dog as a playful interactor and the specific interest ins in how the dog interacts with technology and specifically with screens that are displaying media. Through exploring dog personas, it is hoped to start creating a useful tool for $\mathrm{DCl}$ designers to use, among a skill set. These will be based upon real data gathered from the dog's owners through questionnaires and then correlated into usable persona sets. This work, like Fawley \& Dyson (2012) found, is hoped to open up a discussion around understanding animals, their entanglements whilst creating usable tools for $\mathrm{DCl}$ designers in media technology reflecting further into $\mathrm{HCl}$ and $\mathrm{ACl}$ method transference.

\section{CREATING PERSONAS FOR DOG-MEDIA INTERACTION}

\subsection{Methodological and Philosophical Choices}

As demonstrated above, fictional perspectives and goal-directed perspectives have been used for personas in $\mathrm{ACl}$. Here, a role-based perspective is used for its focus on behaviour (Cooper, 1999) and for it being data-driven and so able to bring much needed clarity and consistency or $\mathrm{ACl}$ allowing a relationship to form between the data and the persona description (Nielsen, 2016). This persona method fits with the ACls animal-centric approach by, even if by proxy, centring the design around real data. The engaging perspective was not used as it molds the mental image of the users together with typical and automated acts (Nielsen, 2016) opening up possibilities of implicit assumptions, and particularly with animals, anamorphic viewpoints. Similarly, fiction-based perspectives were not used so as to avoid extreme characters (Djajdiningrat et al., 2000). The inclusion of owners within the creation of personas, to illicit as real data as possible, minimalizes the human and semiotic artefacts that all $\mathrm{ACl}$ designers face (Frawley \& Dyson., 2012) but is wholly impossible to exclude due to the proxy-nature of the process. In addition, the use of third person linguistically, as in Frawley \& Dyson (2012), will remind the designers of the third perspective.

Of interest for the research were two main user groups: dogs currently situated in people's homes and dogs in rescue centres (kennelled). The two were chosen as they potentially have different requirements and needs (Marinelli et al., 2007) which will be reflected in $\mathrm{DCl}$ media systems requirements. The context of this work is to aid in the development of screen systems for dogs watching media by crafting personas for screen $\mathrm{DCl}$ to aid designers in focusing on and better identifying the requirements of the dog user. Whilst systems have been constructed to support dogs (Hirskyj-Douglas et al., 2016; Zeagler et al., 2016) these are often based on individualistic dog requirements. This work seeks to aid this endeavour by supporting the overarching goal of improving usability with screen devices for dogs.

This study has four stages; (1) questionnaire and persona design, (2) data gathering, (3) encoding into personas and (4) validating personas. The method used here draws on existing methods in $\mathrm{HCl}$ and $\mathrm{ACl}$ towards $\mathrm{DCl}$. The method implemented to design personas was to first research and create questionnaires (1) based upon our previous research (Hirskyj-Douglas et al., 2016; HirskyjDouglas \& Read, 2013). These questionnaires were then piloted to allow improvement through iteration. Once these tools were developed, a method was made to encode the data gathered into personas with dog owners for the first user group and the kennels contacted for the second user group. This method section below describes these processes in further depth.

\subsection{Questionnaire Design}

Questionnaires were chosen to elicit information from the dog owners/ care givers, as a source of habitual and familiarly information. Moser et al. (2012) found three different approaches for questionnaire design; qualitative, quantitative and a mixture of the two. Cooper (1999) initially used a qualitative approach to get behavioural information and identify behavioural patterns, whilst other researchers have used qualitative data through cluster analysis to find context patterns (Miaskiewicz et al., 2008; Faily \& Flechais, 2011; Moser et al., 2011). Referring to Moser at al. (2012)'s decision diagram for special users, this research presumes partial pre-knowledge (ethnographic from other studies included within the field and research), the skills of the researcher and available users, $>100$ sample size and the availability of resources and time. This lead to the conclusion of using a qualitative and quantitative approach to the questionnaire design. 
Taking reference from Robinson et al. (2014) and Frawley \& Dyson (2012) demographic information such as age, gender, breed and if the dog was neutered was gathered. Whilst age and breed has been shown to influence the design of technology for dogs, there has so far been no differentiation shown, in gender and neutered status in technology entanglements. However, studies of animal behaviour have shown some differences along these lines (Serpell, 1995) and so they were included. In addition, pervious persona designers (Neilsen, 2016; Grudin \& Pruitt, 2002) stress the importance of creating narrative among the personas to compose them as realistically as possible and so, as this is how dogs are talked about, this information was gathered.

Qualitative questions made up the bulk of the questionnaire. These included questions mentioned in Robinson et al. (2014) about temperament with children, places the dog had access to and toys the dog had. An open ended question was also given about the generalized behaviour of the dog to gather as much data as possible. Questions were also raised around the technical devices and equipment used by / around the dogs centring around media technology to create scenario based personas. This aimed to enable designers to form a picture around what equipment a dog has ordinarily to help them design around commonplace devices. To aid in this formation of a picture of a dog, a question was asked about the dog's background. The majority of questions centred about the dogs' motivation as, in order for a dog to use a system, without training, it must be motivated to do so (Zimmerman et al., 2007). The last question was an open ended question that allowed owners to add anything they saw as important in $\mathrm{DCl}$ media systems. The same questionnaire was used for both at home and rescue dogs.

\subsection{Questionnaire Administration}

The questionnaire was piloted before use when it was found that participants, ordinary dog owners, were not all aware of the $\mathrm{ACl}$ field and as such, often got confused around questions about their dog's use of technology (TV, iPads, Radio etc.). To counter this, a participant information sheet was designed that gave an introduction into the purpose of the study and the $\mathrm{ACl}$ field. It was also found that the additional comments section of the questionnaire was used for suggestions for technology that the owner believed their dog would benefit from. The final questionnaire used is available at \{anonymized\}. To reach a large audience for 'at home dogs' the questionnaire was put online and advertised through the university, on the researchers own website, via Facebook dog groups, and on dog forums. This was for two months over March and April 2016. Over 250 online responses were initially recorded. To reach kennelled dogs, the researchers visited the kennels in February 2016, where the staff filled in paper based versions, on four dog participants. An example of the data gathered through the survey is given in Table 1.

Table 1: An example of the raw dataset gather from Dog owners for 'at home' dogs.

\begin{tabular}{|l|l|}
\hline Age (Months) & 280 months \\
\hline Breed & Irish Terrier \\
\hline Neutered & Yes \\
\hline Good with children & Yes \\
\hline Does your dog go on walks & Yes \\
\hline Frequency of walks & Everyday. \\
\hline Dogs general behaviour & $\begin{array}{l}\text { Loves people, hates dogs, chases balls, sticks, cars if we are not } \\
\text { careful, typical of the breed }\end{array}$ \\
\hline Background & Purchased from Irish Terrier breeder aged 4 months. \\
\hline Places dog has access too & Whole house and garden, plus woods and fields on walks \\
\hline Is the dog involved in work? & No. \\
\hline Devices dog currently uses & Leads, balls, sticks. \\
\hline $\begin{array}{l}\text { How long do they spend with } \\
\text { these devices? }\end{array}$ & $\begin{array}{l}\text { He would spend all day chasing through the woods if we let him to the } \\
\text { point of collapse! In reality half an hour a day is enough at his age. }\end{array}$ \\
\hline $\begin{array}{l}\text { Does the dog use any } \\
\text { technology devices? }\end{array}$ & Loved to watch dogs and ball based sport on TV \\
\hline $\begin{array}{l}\text { How long does your dog } \\
\text { spend with these devices? }\end{array}$ & Never on his own, joins us to watch TV at night. \\
\hline Motivation & Chase instinct, defending human pack/property, FOOD!!! \\
\hline Favourite Toys & Balls. \\
\hline Any specialist needs & There are no special needs. \\
\hline $\begin{array}{l}\text { What part of the day does the } \\
\text { dog most enjoy }\end{array}$ & Morning walks. \\
\hline Additional Comments & No idea really but his breed needs human contact. \\
\hline
\end{tabular}




\subsection{From Data to Persona}

Most of the data that was gathered was from owners in the United Kingdom, Canada, France and America. An RSPCA centre was involved in the collection of data for the kennelled dog personas. Data was collected in April-May 2016. The study had 197 dog owners participate, with the dogs ranging from 2-192 months (2 unknown) of 114 different breeds and mixes (excluding crossbreeds 49 purebred dogs). $80 \%$ of the dogs were neutered. There were 22 dogs that were involved in a form of work (from agility, blood giving, explosive detection, service dog etc.).

Within the data there were instances where the dog owner did not understand the question, or believed the question to be unintelligent, for instance 'why would a dog use computers' written by owner 62 . To avoid confounds caused by partially completed questionnaires, the contributions from any dog owner who failed to complete two or more fields within the questionnaire was excluded from the study. This left 142 sets of useful dog data for the persona creation process. The dataset in its entirety is available at https://app.xtensio.com/folio/j8dfe $7 \mathrm{t} 0$.

Having decided on the useful data there was a need to do some cleaning and encoding before the data could be used to generate the personas. Examples of cleaning included ensuring consistency of words so they could later be analysed using clustering software. Sometimes words were meaning the same thing but written differently, e.g. mutt or crossbreed, ages were written as months and as years, names were mixed with capitals and lower case (Akita vs Akita) etc. Through the data breed names were changed to standard Kennel Club breed names, ages into months and crossbreed used in place of mutt/mix and other terminology used to imply an unknown specific breed. For analysis, narrative like the number of daily walks was encoded to a numerical representation with 'not often' being mapped to $<=2$ times a week and rarely to $<=5$ times a month (based on words and numbers from other data entries). Around 250 data points were thus tidied up across the data.

Age encoding was additionally found to be problematic as different breeds of dogs' reach maturity at different ages with sexual (6-9 months) and social (12-18 months ending at 24 months) maturity being reached at different times (Overall, 2013). To enable both sexual and social maturity to have been fully reached, and so considering a dog to be adult, the data was cleaned to show all dogs ages over 24 months as adult dogs. Similarly, whilst most vets consider dogs of 7-8 as senior, smaller dogs are often not considered senior until much later (10-12 years) (Overall, 2013). For this reason, the data was coded in such a way that all dogs that were over 96 months were coded as seniors. In this way it was possible to cluster the data for puppy, adult and senior dogs and thus use those clusters to generate personas for those 'ages' of dogs.

A second categorization of the data was along breeds. Due to different types of dogs having different breed characteristics, known as 'Breed Standards' in The Kennel Club (2016b) it was assumed that their abilities along with these traits would influence their interaction with media $\mathrm{DCl}$ technology. The Kennel Club clusters breeds through seven traits which are: gundog, hound, pastoral, terrier, toy, utility and working. A decision was made to focus on the most common traits in regard to breed descriptions. According to Kennel Club breed registration figures (2016a) figures Border Collie and Labrador Retriever breeds are the most popular. These two breeds could also be considered 'instances' of pastorals (Border Collie) and gundogs (Labrador Retrievers). The other five breed traits were not represented in personas within this instance due to the two chosen instances having a higher data set thus representing the breed more accurately. In future iterations, these other breeds could be further represented.

Dogs in rescue situations, such as those in kennels, had different requirements and access to different technology than those who lived with owners. Research from Topal et al. (2012) analysing dogs' behaviour, currently homed but from a rescue situation, revealed that these dogs displayed the same behaviour as a dog that has grown up with their owner. For this reason, dogs from previous rescue situations were not separated from those that had grown up with their owners and only dogs in current rescue situations where considered in this category.

Thus, to create a set of personas along these categories, the data was grouped into the six categories: Age (Puppy, Adult and Senior), Breed (Labrador Retriever and Border Collie) and living situation (Rescue) and analysed through keyword and phrase analysis using NVivo software to give numerical frequencies of the phrases and words. The most frequently used words and phrases within each question for each category formed a theme of concepts which were then used within the persona. This word clustering was achieved by selecting the most frequent words and phrases of the desired data within the question i.e. in 'favourite toys' 'tennis balls' was the overall most popular so would be input into personas or 'gender' to form the gender of the dog. This same process was taken for numerical data where the median was represented. In this instance the persona directly represented the majority of users' thoughts within the selected categorization. 
The presentation of each persona was designed to include a picture, name and a direct quote. The visual design of the personas was chosen to be clean and simple to allow for easy interpretations. This was due to recommendations made by Nielson (2016) for clarity within personas. Other elements decided on for the personas was a section on the dogs' motivation, narrative about behaviour, toys, locations and technology (see Fig 3). The dogs' motivation was chosen to be shown on a scale based around a cluster analysis of phrases and words used within the results giving the $\mathrm{DCl}$ designer a useful visual representation. The personas' names and pictures were fictional details to enable the persona to be more concreate and effective for design (Cooper., 1999) giving a sense of realism to the dataset.

\section{PERSONAS}

Fourteen Border Collies were included in the making of the breed persona Border Collie (Figure 3) and twelve Labrador Retrievers included within the Labrador persona (Figure 4).

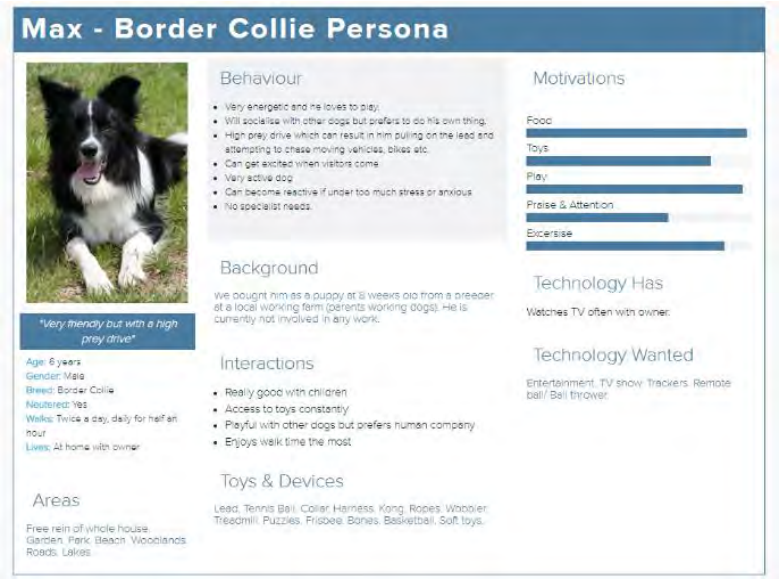

Figure 3: Max: Border Collie Persona

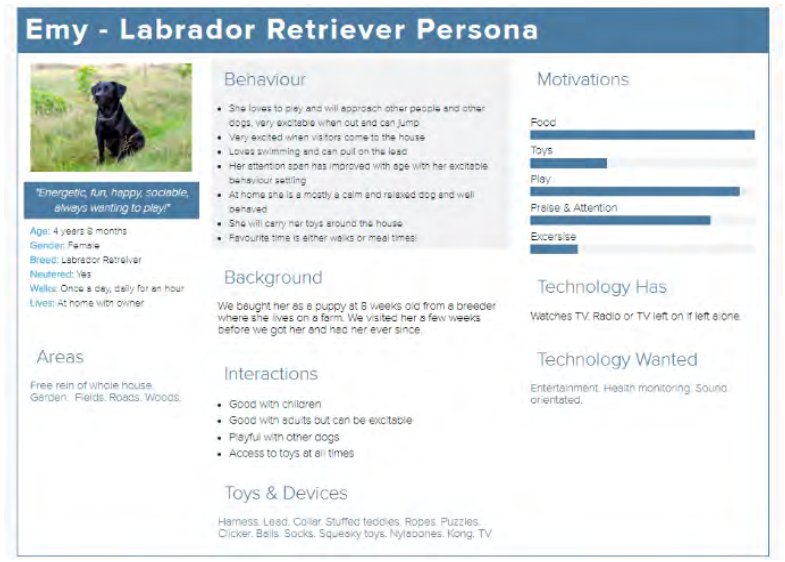

Figure 4: Emy: Labrador Persona

These are slightly lower numbers than expected due to the breed variances and the mixture of breeds being present within the dataset. These two breeds however were the most present within the data.
Twenty-eight puppy dogs were included within the puppy personas (Figure 5), one hundred and ten within the adult persona (Figure 6), and fifty-four in senior dog personas (Figure 7). This demonstrates a bias in the data towards adult dogs, suspected due to the largest age range of the three categories. These personas however had a larger dataset of creation and as such are more applicable than the breed based personas towards generalization.

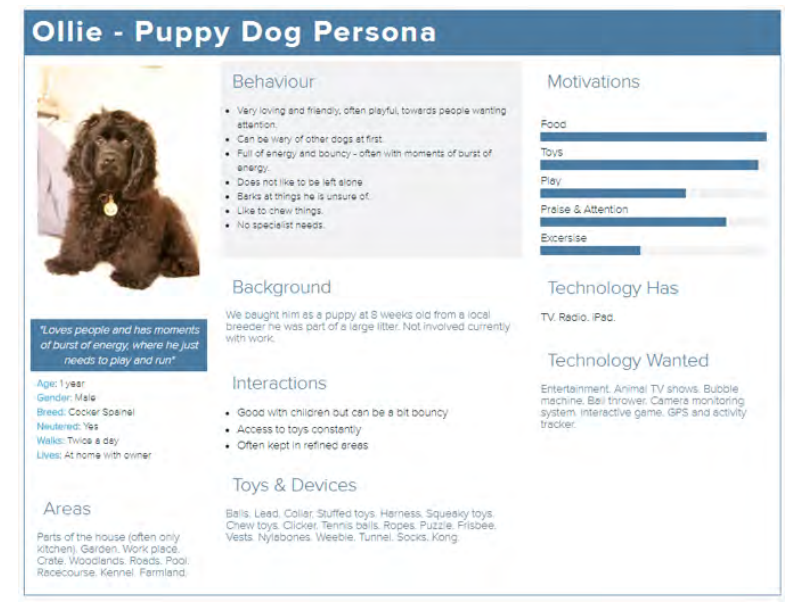

Figure 5: Ollie: Puppy Persona

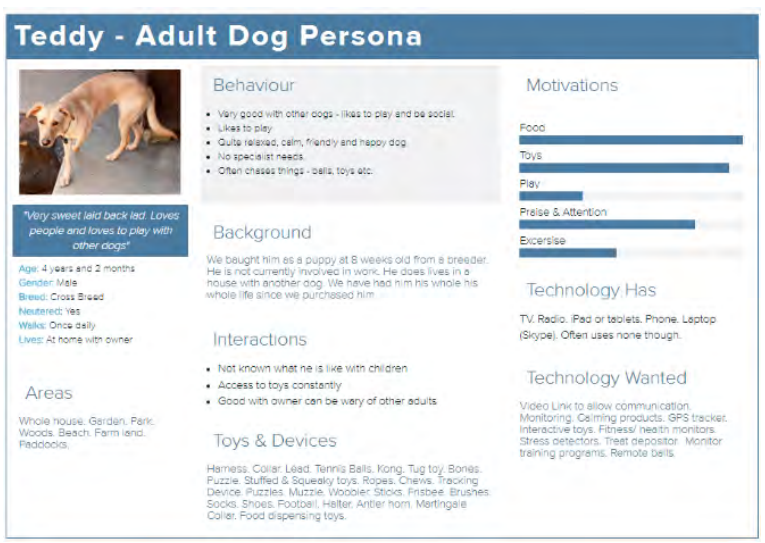

Figure 6: Teddy: Adult Persona

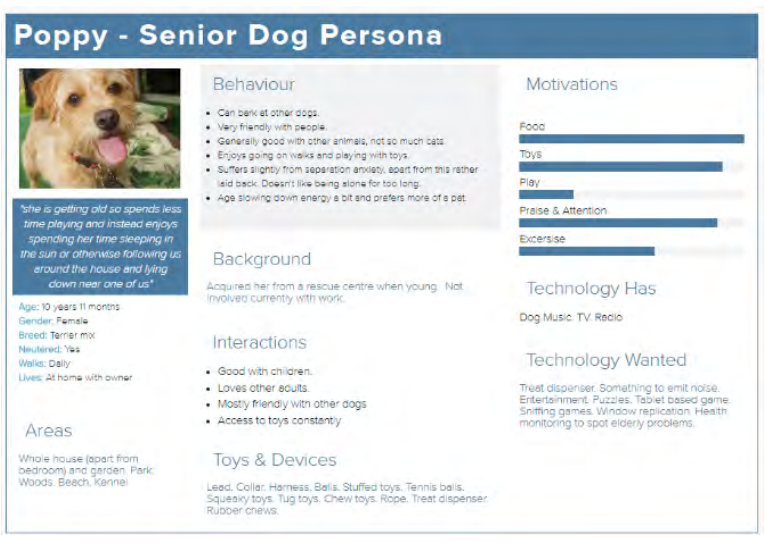

Figure 7: Poppy: Senior Persona

Four dogs were included within the rescue personas (Figure 8). These low numbers were due to both the workers' familiarity of the dogs and the diminutive information known about those held. This is reflected 
within the rescue persona created being sparser than the home dogs. Uniquely, unlike the other personas that preferred food and toys often, the rescue dog persona has the motivation of praise, attention and humans along with constant mention of the need for human interaction within the data.

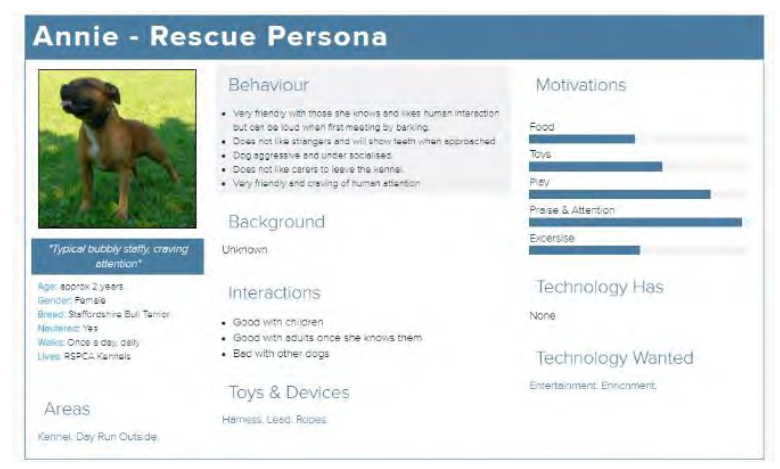

Figure 8: Annie: Rescue Persona

\section{PERSONA VALIDATION}

Personas in $\mathrm{HCl}$ are known to be notoriously hard to validate without continuous iterations through product development. One way of validation, as used here, is to build the personas through a process of data driven development (McGinn and Kotamraju, 2008). Personas have been checked for their usefulness through their attributes for understandably (Chapman et al., 2008). In Chapman et al. (2008) work, they found that the number of attributes added ( $\mathrm{n} 2$ ideal) decreased the prevalence rates towards the end user stressing the need for assessment. In was under this guidance that the personas created were precise with minimal attributes added. Gross et al. (2009) suggest at various stages of a persona development process that reconnecting back with the stakeholders through interviews provides a method of continuous persona validation, this is problematic within $\mathrm{ACl}$ where the dogs can hardly comment on their personas however other stakeholders in $\mathrm{ACl}$, researchers, can be a useful group to validate the personas created.

To that end, researchers in $\mathrm{ACl}$ were contacted and given the persona set and asked to comment along the following questions: (1) Do you, as an expert, see any room for improvement? (2) Would you find personas like these useful? (3) Is this set of personas a specific set? (4) Are these personas efficient? These researchers were chosen as they had previously worked in $\mathrm{ACl}$ studies familiar with dogs and screen technology following Tory \& Mollers (2005) guidelines of using expert reviewers for evaluations. The questions asked were intended to seek ideas for improvement (1), and thoughts on usefulness (2), competence (3) and efficiency (4). Six $\mathrm{ACl}$ researchers took part in this evaluation; three with a background only in $\mathrm{ACl}(\mathrm{A}, \mathrm{C}$ and $\mathrm{D})$, one from mainly a $\mathrm{HCl}$ background $(B)$ and one with an animal behaviour background (Table 2 ).

Table 2: Table showing $\mathrm{DCl}$ researchers comments on validating the personas.

\begin{tabular}{|c|c|l|l|}
\hline Expert & $\begin{array}{l}\text { Experienc } \\
\text { e of ACl } \\
\text { (out of 5) }\end{array}$ & $\begin{array}{l}\text { Research } \\
\text { Background }\end{array}$ & Comments \\
\hline A & 5 & $\begin{array}{l}\text { Animal } \\
\text { Computer } \\
\text { Interaction }\end{array}$ & $\begin{array}{l}\text { Thought the personas were defiantly useful and can be used a great } \\
\text { tool for both new people in the field and the experienced researchers } \\
\text { working with various animals. Wondered if there were any trade-offs } \\
\text { to the personas for behaviour and technology and what other breeds } \\
\text { might fit into each persona as this might be helpful for researchers in } \\
\text { DCl design. Suggested changing the technology wanted section into } \\
\text { a bar chat to classifies different technologies but did for its detail, but } \\
\text { this did dilute trends. Lastly, the researcher questioned the amount of } \\
\text { time each dog exercise to help with durability and robust-ability for } \\
\text { DCl products. Overall found to be a really good survey of pet dog; } \\
\text { did note that abused or behavioural sensitive dogs were missing, } \\
\text { hinted at in rescue personas, from the set. }\end{array}$ \\
\hline B & 4 & $\begin{array}{l}\text { Thought the personas were really nice. Researcher would have also } \\
\text { wanted to include the category of people in diffractions (new/ known/ } \\
\text { favourite), as this affects the general behaviour of the dog when } \\
\text { there are those motivators/influences and/or interactions. Research } \\
\text { did state that the personas could be improved thought a section } \\
\text { about problem behaviours and if the dog has a limit to the amount of } \\
\text { dogs within tis environment. She stated these personas would be } \\
\text { more efficient if there was a history of what was already } \\
\text { tried/successful and add some recommendations made upon these. }\end{array}$ \\
\hline
\end{tabular}




\begin{tabular}{|c|c|l|l|} 
& & & $\begin{array}{l}\text { Lastly, the researcher suggested putting these online and opening } \\
\text { them up for comments to enable a joint expertise to form. }\end{array}$ \\
\hline C & 5 & $\begin{array}{l}\text { Animal } \\
\text { Computer } \\
\text { Interaction }\end{array}$ & $\begin{array}{l}\text { Researcher thought this set was useful, particularly as a template for } \\
\text { different ACl scenarios but would benefit from having how dogs } \\
\text { currently use technology (paws or nose) along with levels of } \\
\text { excitement. This expert also asked if this tool was just for designers } \\
\text { or also dog owners, as they suggest a tool like this could also be } \\
\text { used by owners to raise awareness on both the owners and } \\
\text { designers about good and bad practice. }\end{array}$ \\
\hline D & 5 & $\begin{array}{l}\text { Animal } \\
\text { Computer } \\
\text { Interaction }\end{array}$ & $\begin{array}{l}\text { Researcher stated these personas would be helpful, in particular, for } \\
\text { someone to broadly gain a picture of what designing for dogs' } \\
\text { entails, dog differentiation, and some key things they should } \\
\text { consider. Suggest adding in what kind of work/job they have and } \\
\text { what this entails as there is often confusion in DCl over this. }\end{array}$ \\
\hline E & 3 & $\begin{array}{l}\text { Mainly } \\
\text { Animal } \\
\text { Behaviour } \\
\text { recently } \\
\text { moved to } \\
\text { ACl }\end{array}$ & $\begin{array}{l}\text { Researcher suggests personas to align with current "personality" } \\
\text { assessments literature in existence to improve such as Dog } \\
\text { Personality Questionnaire (2008) and C-BARQ (2005). Researcher } \\
\text { stated as a designer they would like more questions on the } \\
\text { parameter of the animal such as sound sensitivity, tendencies } \\
\text { towards light, OCD and focused behaviours, mouth or paws use, dog } \\
\text { arousal and confidence level. They then suggested these could be } \\
\text { tested through rating different toys/interfaces, ratings for the dog and } \\
\text { then a measure of compatibility. }\end{array}$ \\
\hline
\end{tabular}

All of these researchers found the personas useful with the main suggestions for improvement being around interaction modalities such as paws or nose ( $C$ and $E$ ), more information around behavioural reactions ( $A, B$ and $E)$, more about the dogs' work (D) and more on people/dog interactions (B). Overall the experts agreed that the persona set would be helpful, with comments made about the set being available online for open forum comments (B), as a template (C) and as a tool for dog owners (C). Questions were also asked around trends spotted in the data gathering process $(A)$.

To further validate the created personas in a hypothetical manner, the real world system of DogTV (2016) a specially made dog TV channel, designed without the personas, was evaluated against the persona set to see if the proposed personas could help product improvement. DogTV (2016) relies upon the dog having access to a TV device, which all the at home dogs had, but the rescue dog (Annie) did not; in this way the persona set would flag up that there is a group of dogs who would not benefit from DogTV. Teddy and Ollie had had access to tablets and so, DogTV's expansion into tablets fits in well with the at home users' technology. Max, with his treadmill and puzzles might suggest that the DogTV company look into using these toy items to interact with the TV content; Ollie and Teddy might want some radio content and as the personas suggest a change in requirements with the age of the dog, DogTV could expand its range of videos into age appropriate viewing to allow for the variances. It is through conversations, like these mentioned here with the personas on usability of a device, that personas provide the technology, in this instance DogTV, with real world users data to help product improvement.

These expert reviews and real-world systems analysis have not been used exclusively to validate as another scenario of use for these personas is an education tool to those new into the $\mathrm{ACl}$ field for introducing and discussing different dog requirements and needs. These six personas created have been used successfully and been found useful to initially design dog screen systems in a workshop for designing technology for dogs as a way of representing the end-users (ATLAS., 2017). This further validates this tool as not only useful to practitioners in the field, but also towards educating those new to the $\mathrm{ACl}$ field and the commercial market.

\section{DISCUSSION AND FUTURE WORK}

This section discusses the variances spotted within the data during encoding, the tension when creating dog personas between generalization and individualization, the use of questionnaire data as a storehouse for personas and the findings from the persona validation.

During data analysis it become apparent that, as mentioned above, rescue dogs had some very different user requirements to that of those dogs living with their owner(s). This amounts to home dogs having their needs for love, affection and belongingness met during their normal home situations - something that is not possible in most 
rescue instances. Joan (2008) modelled some of this in a hierarchic theory of a dogs' needs based on Maslow's pyramid. In Joan's pyramid, coined Muttlows Hierarchy of Needs, the toys and entertainment aspect is a level above the need for love, affection and belongingness (Joan, 2008). This suggests that $\mathrm{DCl}$ technology should not be a main concern for dogs who don't have their underlying needs met. The $\mathrm{ACl}$ community should perhaps question the placing of technology into such situations.

The method presented here compliments Robinson et al. (2014) and Fawley \& Dysons (2012) exploration of personas in $\mathrm{ACl}$. Using cluster analysis, it was found that phrase rather than word analysis was helpful in creating sentence structures that resembled the original data. Clustering was more straightforward the more data there was present (i.e. adult dogs vs. rescue dogs) as there were more correlation points. By using correlation, some of the individual stories got lost and this exposed a conflict of interest between actual representation and generalized representation. It was to avoid over generalizing that an overall dog persona from the data was not developed; rather characteristics and ages were presented to highlight the differences within the species, both through physiological, age and location.

In creating the personas, a storehouse of information was created. This storehouse can be used by other researchers, and grown in future $\mathrm{DCl}$ work, to create other persona sets according to the different needs for design. Whilst the current storehouse has a media screen focus, much of the data is transferable and useful to other technology 'behaviour innovations. For instance, there were a number of working dogs within the study, that could be used to make working dog personas. Further data collection could be done to create an expanded persona set from which designers could choose according to their focus - one could imagine a set of puppies and a set of sheepdogs for example. As suggested previously personas could be correlated against The Kennel Club 'Breed Standards' to be applicable towards a type of breed rather than an individual breed instance.

The persona set suggested here is currently being used in design. This will aid in the further validation of the set in use. Going forward, the usefulness of the personas could be validated to further understand the user's needs creating further user centric design stance in $\mathrm{DCl}$ and additional validation could also be done of the personas through observing dogs doing real tasks within $\mathrm{DCl}$ to build personas from these instances to base the personas further around a dogs seen interactivity as done within $\mathrm{HCl}$ (Spool., 2011). However, as the field is relatively new, there are few instances of dogs interacting with technology to base these personas off.

\section{CONCLUSION}

The research here presents a set of dog personas, a method for generating dog personas and a storehouse of data being available to other researchers working in $\mathrm{ACl}$ and $\mathrm{DCl}$. This paper explores creating personas for two popular different breeds (Labrador Retrievers and Border Collies) for diverse age groups (puppy, adult and senior dogs) and challenging living situations (rescue dogs). These personas can be used as in the early stage of designing for $\mathrm{DCl}$ to help focus the designer on a user which can be inaccessible. This builds on Robinson et al. (2014) and Fawley \& Dyson (2012) work, helping to support the persona approach in $\mathrm{DCl}$, thus $\mathrm{ACl}$. Particularly these personas help $\mathrm{DCl}$ working with media devices as they are scenario based upon this situation.

Another output from this study is through the creation of a storehouse of 197 varying dogs' data to allow $\mathrm{DCl}$ researchers to encode their own persona set from this data. In this way even if a $\mathrm{DCl}$ media researcher does not have access to a large population of dogs, the data can help focus the designer on the end-user dog requirements initially. Alternatively, $\mathrm{DCl}$ researchers could take individual dog's data to illicit user requirements from. Lastly, these personas have been validated by both evaluating the personas to see if they can improve existing $\mathrm{DCl}$ technology and with experts in the field of DCl who would use these personas. Researchers in $\mathrm{DCl}$ found these personas useful but did suggest improvements by expanding the set into more dogs with further details about the animals behaviour. The work here also helps to illuminate to $\mathrm{DCl}$ researchers that the dogs physiological (breed and age) as well as living status (pet vs. rescue) has an impact upon the end-user(s) requirements. These personas however are an incremental process of refinement rather than a product development phase and could be modified as the knowledge around the $\mathrm{DCl}$ and $\mathrm{ACl}$ field grows. This paper helps the overall field aims of helping to bring successful interaction to $\mathrm{DCl}$ technology for dogs by allowing the conceptual stage of dog computer technology to be focused around the users' needs instead of the later stage of end-user testing. Lastly, this paper successfully demonstrates the method transference between $\mathrm{ACl}$ and $\mathrm{HCl}$ giving guidance to those also wishing to transfer methodologies to grow the combined knowledge strengthening both fields and $\mathrm{HCl}$ ability to design for fringe users. 


\section{REFERENCES}

ACl@BHCl. (2015) Animal Computer Interactions at British Human Computer Interaction Workshop.

Aspling, F., Juhlin, O., Chiodo, E. (2015) Smelling, pulling, and looking: unpacking similarities and differences in dog and human city life. In: Proceedings of ACE'15.

ATLAS. (2017). Designing Technology for Dogs: A Workshop to Empower your Pooch. Available at: atlas.colorado.edu/events/dog-tech/. Last accessed 14.05.17.

Blomkvist, S. (2002) The User as a personality. In Using Personas as a tool for design. Position paper for the course workshop "Theoretical perspectives in Human-Computer Interaction" at IPLab, KTH.

C-BARQ. (2016) Canine Behavioural \& Research Questionnaire. Avaliable at: http://veapps.vet.upenn.edu/cbarq/. Last accessed 08.01.17.

Chapman, C.N., Love, E., Milham, R.P., EIRif, P. and Alford, J.L. (2008) Quantitative evaluation of personas as information. In Proceedings of the Human Factors and Ergonomics Society Annual Meeting. SAGE Publications. 1107-1111

Cooper, A. (1999) The inmates are running the asylum. Indianapolis, IA: SAMS/Macmillan.

Djajadiningrat, J. P., Gaver, W. W. and Frens, J. W. (2000) Interaction relabeling and extreme characters: methods for exploring aesthetic. Proceedings of the 2000 Conference on Designing Interactive Systems (DIS '02): Processes, practices, methods, and techniques, New York City, NY, US. 66-71

DogTV. (2016) DogTV Home. [online] Available at: http://dogtv.com/.

DPQ. (2016) Dog Personality Questionnaire. Avaliable at: http://gosling.psy.utexas.edu/wpcontent/uploads/2014/10/DPQ-forms-andscoring-keys.pdf. Last accessed 08.01.17.

Faily, S. and Flechais, I. (2011) Persona cases: a technique for grounding personas. In Proceedings of the SIGCHI Conference on Human Factors in Computing Systems. ACM. 2267-2270

Frawley, J.K. and Dyson, L.E. (2014) Animal personas: acknowledging non-human stakeholders in designing for sustainable food systems. In Proceedings of the 26th Australian Computer-Human Interaction Conference on Designing Futures: The Future of Design. ACM. 21-30

Freydenson, E. (2002) Bringing your personas to life in real life. Boxes and Arrows.
Gross, T., Gulliksen, J., Kotzé, P., Oestreicher, L., Palanque, P., Prates, R.O. and Winckler, M. (2009) Human-Computer Interaction-INTERACT 2009: 12th IFIP TC 13 International Conference, Uppsala, Sweden. Springer. 525

Grudin J, Pruitt J. (2002) Personas, participatory design and product development: An infrastructure for engagement. InPDC. 144-152

Haraway, D.J. (2008) When species meet. Vol. 224. $U$ of Minnesota Press.

Hirskyj-Douglas, I., Read, J.C., Juhlin, O., Väätäjä, H., Pons, P. and Hvasshovd, S.O. (2016) Where $\mathrm{HCl}$ meets $\mathrm{ACl}$. In Proceedings of the 9th Nordic Conference on Human-Computer Interaction. ACM. 136

Hirskyj-Douglas, I., J. C. Read, and B. C. Cassidy. (2016) A dog centred approach to the analysis of dogs' interactions with media on TV screens. International Journal of Human-Computer Studies.

Hirskyj-Douglas, I and Read, J.C. (2014) Who is really in the center of Dog Computer Interaction? Advance Computer Entertainment (ACE)' 14. ACM. Madeira.

Hirskyj-Douglas, I. and Read, J.C. (2013) Animal Computer Interaction Design. ACM-W. Manchester

Joan. (2016) Muttlows Hierarchy of Needs.: The Inquisitive Canine. Available at: http://inquisitivecanine.com/fido-

fundamentals/muttlows-hierarchy-of-needs/.

Nielsen, L. (2016) Personas. The Encyclopaedia of Human-Computer Interaction. 2nd Edition.

Mancini, C. (2016) Towards an animal-centered ethics for Animal-Computer Interaction. International Journal of Human-Computer Studies. SI: ACl.

Mancini, C. (2011) "Animal-computer interaction: a manifesto." interactions 18.4: 69-73.

Mancini, C., van der Linden, J., Kortuem, G., Dewsbury, G., Mills, D. and Boyden, P. (2014) UbiComp for animal welfare: envisioning smart environments for kennelled dogs. In: Proceedings of ACM Ubicomp'14, ACM Press.

Mancini, C., Juhlin, O., Cheock, A.D., van der Linden, J. and Lawson, S. (2014) Animalcomputer interaction $(\mathrm{ACl})$ : pushing boundaries beyond'human'. In Proceedings of the 8th Nordic Conference on Human-Computer Interaction: Fun, Fast, Foundational, ACM, 833-836.

Mancini, C., Harris, R., Aengenheister, B. and Guest, C. (2015) Re-centering multispecies practices: a canine interface for cancer detection dogs. In Proceedings of the 33rd Annual ACM 
Conference on Human Factors in Computing Systems. ACM. 2673-2682.

McGinn, J.J. and Kotamraju, N. (2008) Data-driven persona development. In Proceedings of the SIGCHI Conference on Human Factors in Computing Systems. ACM. 1521-1524

Marinelli, L., Adamelli, S., Normando, S. and Bono, G. (2007) Quality of life of the pet dog: Influence of owner and dog's characteristics. Applied Animal Behaviour Science, 108(1). 143-156

Marsden, N. and Haag, M. (2016) Evaluation of GenderMag Personas Based on Persona Attributes and Persona Gender. In International Conference on Human-Computer Interaction. Springer International Publishing. 122-127

Miaskiewicz, T. and Kozar, K.A. (2011) Personas and user-centered design: How can personas benefit product design processes?. Design Studies, 32(5). 417-430

Westerlaken, M., and Gualeni, S. (2014) "Felino: The philosophical practice of making an interspecies videogame." The Philosophy of Computer Games Conference.

Milton, K. (2005) Anthropomorphism or egomorphism?: The perception of non-human persons by human ones. In J. Knight (Ed.), Animals in Person: Cultural Perspectives on Human-Animal Intimacies. Oxford: Berg. 255271

Moore, A. G. (1991) Crossing the chasm. Harper Collins Publishers, New York.

Moser, C., Fuchsberger, V. and Tscheligi, M. (2011) Using probes to create child personas for games. In Proceedings of the 8th International Conference on Advances in Computer Entertainment Technology. ACM.

Moser, C., Fuchsberger, V., Neureiter, K., Sellner, W. and Tscheligi, M. (2012) Revisiting personas: the making-of for special user groups. In $\mathrm{CHI} 12$ Extended Abstracts on Human Factors in Computing Systems. ACM. 453-468

Overall, K. (2013) Manual of Clinical Behavioral Medicine for Dogs and Cats. Mosby.

Pons, P., Jaen, J. and Catala, A. (2015) Envisioning future playful interactive environments for animals. In: More Playful User Interfaces. Springer, Singapore. 121-150

Pruitt, J. and Adlin T. (2006) The Persona Lifecycle: Keeping People in Mind Throughout Product Design. San Fransisco: Morgan Kaufmann.

Racca, A. E. Amadei, S. Ligout, K. Guo, K. Meints, D. Mills. (2010) Discrimination of human and dog faces and inversion responses in domestic dogs (Canis familiaris). Anim. Cogn., 13(3), 525-533
Robinson, C., Mancini, C. van der Linden, J., Claire and Harris, R. (2014) Empowering assistant dogs: an alarm interface for canine use. IN: ISAWEL'14 Intelligent Systems for Animal Welfare. London.

Scott, J. P. and Fuller, J. L. (2012) Genetics and the Social Behavior of the Dog. University of Chicago Press.

Second Livestock (2016) Animal - Centered Design. Available at: http://www.secondlivestock.com/public/acd.php.

Serpell, J. (1995) The domestic dog: its evolution, behaviour and interactions with people. Cambridge University Press.

Sinha, R. (2003) Persona development for information-rich domains. In $\mathrm{CHI} 03$ extended abstracts on Human factors in computing systems. ACM. 830-831

Spool., J. (2016) When does a persona stop being a persona? User Interface Engineering. Available at:

https://www.uie.com/brainsparks/2011/12/15/wh en-does-a-persona-stop-being-a-persona/. Last accessed 27.12.2016.

Tan, R.T.K.C., Cheok, A.D., The, J.K.S. (2006) Metazoa Ludens: mixed reality environment for playing computer games with pets. IJVR, 5 (3). 53-58

The Kennel Club. (2016a) Breed Registration Figures. Available at: http://www.thekennelclub.org.uk/registration/bree d-registration-statistics/. Last accessed 02.12.2016.

The Kennel Club. (2016b) Breed Standards Information: Dog Breeds \& groups. Available at: http://www.thekennelclub.org.uk/activities/dogshowing/breed-standards/. Last accessed 02.12.2016.

Topál, J. and Gácsi, M. (2012) Lessons we should learn from our unique relationship with dogs: an ethological approach. Crossing Boundaries: Creating Knowledge about Ourselves with Other Animals. 163-188.

Tory, M., and Moller, T. (2005). Evaluating visualizations: do expert reviews work?. IEEE computer graphics and applications, 25(5), 8-11.

Väätäjä, Heli K., and Emilia K. Pesonen. (2013) Ethical issues and guidelines when conducting $\mathrm{HCl}$ studies with animals. $\mathrm{CHI} 13$ Extended Abstracts on Human Factors in Computing Systems. ACM.

Van den Broek, E.L. (2016) Animal-Computer Interaction (ACl): A survey and some suggestions. Animal Computer Interaction Symposium. Measuring Behaviour. 
Weilenmann, A. and Juhlin, O. (2011) Understanding people and animals: the use of a positioning system in ordinary human-canine interaction. In Proceedings of the SIGCHI conference on human factors in computing systems. ACM. 2631-2640

Zeagler, C., Zuerndorfer, J., Lau, A., Freil, L., Gilliland, S., Starner, T., and Jackson, M. M. (2016) Canine computer interaction: towards designing a touchscreen interface for working dogs. In Proceedings of the Third International Conference on Animal-Computer Interaction ( $p$. 2). ACM.

Zimmerman, J., Forlizzi, J. and Evenson, S. (2007) Research through design as a method for interaction design research in $\mathrm{HCl}$. In Proceedings of the SIGCHI conference on Human factors in computing systems. ACM. (2007) 493-502 